\title{
Is COPD associated with alterations in hearing? A systematic review and meta-analysis
}

This article was published in the following Dove Medical Press journal:

International Journal of COPD

\begin{abstract}
Arash Bayat ${ }^{\prime}$
Nader Saki ${ }^{2}$

Soheila Nikakhlagh ${ }^{2}$

Golshan Mirmomeni ${ }^{3}$

Hanieh Raji ${ }^{4}$

Hossein Soleimani'

Fakher Rahim ${ }^{5}$

'Department of Audiology, Hearing Research Center, Imam Khomeini Hospital, Ahvaz Jundishapur University of Medical Sciences, Ahvaz, Iran; ${ }^{2}$ Department of Otorhinolaryngology, Hearing Research Center, Ahvaz Jundishapur University of Medical Sciences, Ahvaz Iran; ${ }^{3}$ Department of Biostatistics and Epidemiology, School of Health, Ahvaz Jundishapur University of Medical Sciences, Ahvaz, Iran; ${ }^{4}$ Department of Internal Medicine, Air Pollution and Respiratory Diseases Research Center, Ahvaz Jundishapur University of Medical Sciences, Ahvaz, Iran; ${ }^{5}$ Department of Molecular Medicine, Health Research Institute, Thalassemia and Hemoglobinopathies Research Centre, Ahvaz Jundishapur University of Medical Sciences, Ahvaz, Iran
\end{abstract}

\footnotetext{
Correspondence: Fakher Rahim Department of molecular medicine, Health Research Institute, Thalassemia and Hemoglobinopathies Research Center, Ahvaz Jundishapur University of Medical Sciences, PO Box 61537-15794, Ahvaz, Iran

Tel +986133367652

Email bioinfo2003@gmail.com
}

\begin{abstract}
Background and aims: COPD is an irreversible or persistent airflow obstruction, which affects up to 600 million people globally. The primary purpose of this systematic review was to explore the COPD-based alteration in the auditory system function by conducting a quantitative analysis of presently published data.
\end{abstract}

Materials and methods: We systematically searched seven diverse electronic databases and manual searching of references to identify relevant studies. Data from the selected studies were rated by two investigators independently in a blinded fashion. Meta-analysis was done on pooled data using Cochrane's Review Manager 5.3.

Results: Sixteen articles received suitable scores and were thus included for further processes. Hearing loss (HL) was defined as a change in pure tone audiometry (PTA) thresholds, auditory brainstem response (ABR), and auditory $\mathrm{P} 300$ parameters. ABR wave was significantly elongated in patients with COPD than in controls (standardized mean difference [SMD] $=0.27,95 \%$ CI: $0.05-0.48, P=0.02)$. PTA was significantly higher in patients with COPD when compared with controls (SMD=1.76, 95\% CI: $0.43-3.08, P=0.0004)$. We found that patients with COPD had a significantly higher latency than controls ( $\mathrm{SMD}=1.30,95 \% \mathrm{CI}: 0.79-1.80, P=0.0001$ ).

Conclusion: COPD patients had considerably greater incidence of HL when compared with controls. Interestingly, although the mean PTA thresholds at every frequency for COPD patients were higher than those for controls, these values were still in the slight to mild HL ranges. Prolonged ABR wave latencies in the COPD patients suggest retro-cochlear involvement. Thus, COPD most frequently clusters with HL, but it is worth noting that alteration in hearing is not always recognized by medical experts as a frequent comorbidity associated with COPD.

Keywords: COPD, hearing loss, systematic review, meta-analysis

\section{Introduction}

COPD is an irreversible or persistent airflow obstruction, which affects up to 600 million people globally. COPD is presently one of the major causes of morbidity and mortality in people suffering from chronic illnesses. COPD prevalence is an increasing problem in old age, and globally, the number of COPD patients aged 65 or over is growing. ${ }^{1}$ Moreover, the main healthcare resources are expended on COPD as well as beyond its comorbidities, of which half of the costs are attributable to hospital stay. $^{2}$ In recent years, the use of home care services, as well as the involvement of the patients in observing and managing their illness in cooperation with the health professionals have increased. ${ }^{3}$ The central nervous function may be adversely affected by COPD. ${ }^{4}$ Several studies have also been performed on the effect of COPD on different structures of the auditory system in COPD patients.

The mechanotransduction mechanism of the inner ear is extremely reliant on the oxygen supply to the cochlea, so that any significant reduction in oxygen locally may 
have a marked effect on hearing sensitivity. ${ }^{5}$ Atis et $\mathrm{al}^{6}$ and Gupta et $\mathrm{al}^{7}$ recorded auditory brainstem responses (ABRs) in individuals with airflow obstruction and found that auditory nerve and brainstem functions have been influenced in these patients. Conversely, Abdel Dayem et $\mathrm{al}^{8}$ and Cunningham et $\mathrm{al}^{9}$ reported absence of significant changes in auditory function between chronic respiratory insufficiency and control participants.

Pure tone audiometry (PTA) is a behavioral test used to measure hearing sensitivity and to determine the degree and type of hearing impairment. ${ }^{11}$ ABRs are acoustically stimulated signals that represent synchronous neural activation along the auditory pathways from the auditory nerve to the brainstem nuclei. ABRs can be used for hearing threshold estimations and for neurodiagnostic purposes. ${ }^{12}$ The recording results are represented as a series of positive peaks (I-V) that are recorded from the human scalp within $10 \mathrm{~ms}$ of a single appropriate acoustic stimulus. The first two peaks (waves I and II) are generated by the auditory nerve, and the subsequent peaks (waves III-V) actually have multiple generators, meaning that they are produced by the pooled electrical activity of several nuclei in the auditory brainstem. The auditory P300 is an event-related potential commonly elicited in signal detection tasks. The P300 provides an objective measure of cognitive function in the auditory system. ${ }^{10}$

The primary purpose of this systematic review was to explore the COPD-based alteration in the auditory system function by conducting a quantitative analysis of presently published data. We compared PTA thresholds, ABR, and auditory P300 parameters in COPD patients and controls. Besides, the results of this review may provide an insight into the potential association between COPD and hearing loss (HL).

\section{Materials and methods}

\section{Search strategy}

We systematically performed a literature search according to PRISMA guidelines. Potential articles were identified through the following electronic databases: MEDLINE, PubMed, EMBASE, Biosis Preview, ISI Web of Science, National Institute for Health and Clinical Excellence, and Scopus. The search terms included (hearing loss OR hearing impairment OR hearing damage OR hearing difficulty OR hearing disorder OR auditory impairment OR auditory damage OR auditory dysfunction OR deaf) AND (COPD). The search was conducted up to April 2018 with no language limits.

\section{Inclusion and exclusion criteria}

All observational studies using a prospective cohort or crosssectional design (studies with controls) on hearing assessment in adult COPD patients using conventional PTA, ABR, or auditory P300 were included. Studies in which the control population was not subjected to the same hearing tests as the COPD patients, the diagnosis of COPD was based on selfreport, or the hearing assessment was not standardized were excluded. Furthermore, letters, editorials, commentaries, conference abstracts, animal or biochemical studies, and case reports were not eligible for evaluation.

\section{Study selection}

A spreadsheet was used for this purpose accounting for authors, study titles, study design, outcomes, type of hearing screening measure, and statistical analysis. Data from the selected studies were rated by two investigators (AB and FR) independently in a blinded fashion. Scores were then compared using the Pearson correlation coefficient to determine the interrater reliability. Correlation coefficient $>0.80$ was considered acceptable for a significance level of $\alpha<0.05$. All divergence among reviewers was resolved by consensus.

The articles considered eligible were further subjected to "quality assessment" using the modified Newcastle-Ottawa Quality Assessment scale for nonrandomized studies.

\section{Statistical analysis}

We used the standardized weighted mean difference with 95\% CI to estimate a pooled effect size for each outcome of interest. Data were pooled with both fixed effects and random effects models. Statistical heterogeneity was explored using the chi-squared test at 5\% significance level $(P<0.05)$. $I^{2}$ statistic was used to quantify variation across studies results. Between-studies variance was also estimated using tau-squared $\left(\tau^{2}\right)$ statistic, and funnel plot was used to investigate publication bias visually. All analyses were conducted with Review Manager Software version 5.3 (The Nordic Cochrane Center).

\section{Results}

A total of 116 articles were found through the initial search; 18 other studies were recognized through a reference search of the selected studies. After screening of titles and abstracts, 32 articles entered the full-text articles review process, and 11 of these were excluded (Figure 1). Finally, 16 of the potentially selected studies received suitable scores and were 


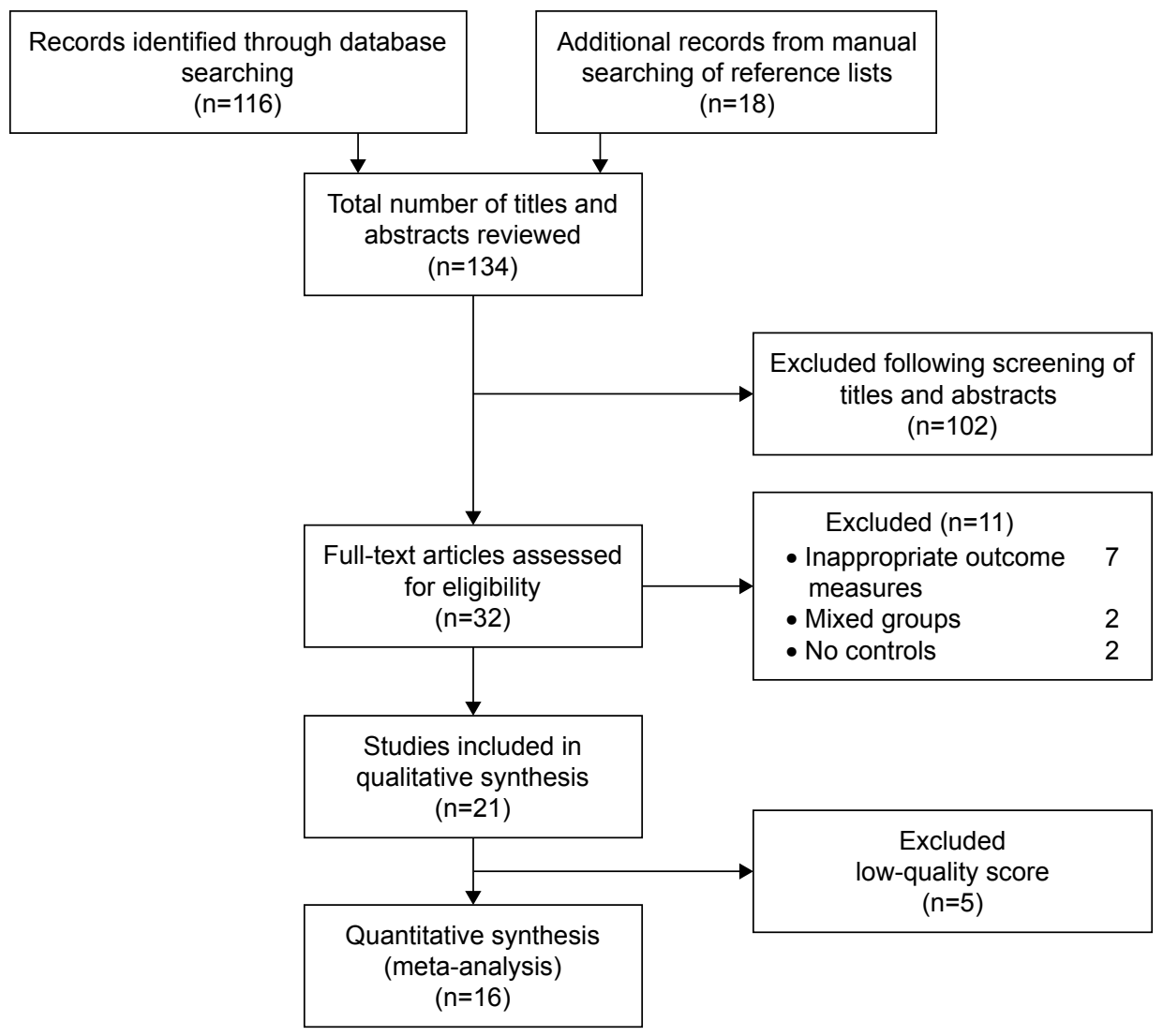

Figure I Flow diagram for study selection of studies looking at the effects of COPD on hearing function.

thus included for further processes. The basic information and characteristics of the recruited studies are listed in Table 1.

We used the Newcastle-Ottawa scale to assess the quality of selected studies. All included studies received overall scores of $>6$ (Table 2 ).

\section{$A B R$ wave latencies}

Left ear

ABR waves' latencies of the left ear were found only in seven studies. ${ }^{711-16}$ Though the heterogeneity was relatively high, all absolute peak latencies (waves I-V) were significantly

Table I Characteristics of the included studies

\begin{tabular}{|c|c|c|c|c|}
\hline Author(s) & Country & Publication year & $\begin{array}{l}\text { Participants } \\
\text { (controls/COPDs) }\end{array}$ & $\begin{array}{l}\text { Method of hearing } \\
\text { assessment }\end{array}$ \\
\hline Atiş et $\mathrm{al}^{6}$ & Turkey & 2001 & $2|/ 2|$ & ABR \\
\hline Kamenski et al $^{18}$ & Austria & 2015 & $97 / 97$ & PTA \\
\hline El-Kady et $\mathrm{al}^{5}$ & Egypt & 2006 & $30 / 60$ & PTA, ABR \\
\hline Abdel Dayem et $\mathrm{al}^{8}$ & Egypt & 2017 & $25 / 100$ & PTA \\
\hline Cunningham et $\mathrm{al}^{9}$ & USA & 1985 & $12 / 15$ & PTA \\
\hline Kabali and Kabali ${ }^{16}$ & India & 2013 & $30 / 30$ & $A B R$ \\
\hline Shalabi et al $^{15}$ & Egypt & 2012 & $15 / 40$ & $A B R$ \\
\hline Gupta et $\mathrm{al}^{7}$ & India & 2008 & $40 / 40$ & $\mathrm{ABR}$ \\
\hline Gupta et al ${ }^{19}$ & India & 2013 & $40 / 40$ & Auditory P300 \\
\hline Mourad et al ${ }^{20}$ & Egypt & 2017 & $20 / 40$ & Auditory P300 \\
\hline Al-Tahan et $\mathrm{al}^{2 \mathrm{I}}$ & Saudi Arabia & 2002 & $25 / 32$ & Auditory P300, ABR \\
\hline Kayacan et $\mathrm{al}^{14}$ & Turkey & 2001 & $20 / 32$ & $\mathrm{ABR}$ \\
\hline Parlewar and Shaikh"I & India & 2016 & $50 / 50$ & $\mathrm{ABR}$ \\
\hline Waseem $^{12}$ & India & 2018 & $30 / 25$ & $\mathrm{ABR}$ \\
\hline Hafez et al ${ }^{13}$ & Egypt & 2009 & $30 / 30$ & ABR \\
\hline Parlewar and Shaikh ${ }^{17}$ & India & 2016 & $50 / 50$ & $A B R$ \\
\hline
\end{tabular}

Abbreviations: ABR, auditory brainstem response; PTA, pure tone audiometry. 
Table 2 Assessment of study quality (Newcastle-Ottawa scale quality indicator)

\begin{tabular}{|c|c|c|c|}
\hline Author(s) & Selection & Comparability & Outcome \\
\hline Atiş et $\mathrm{al}^{6}$ & $4 / 5$ & $1 / 2$ & $2 / 3$ \\
\hline Kamenski et al ${ }^{18}$ & $4 / 5$ & $1 / 2$ & $2 / 3$ \\
\hline El-Kady et $\mathrm{al}^{5}$ & $4 / 5$ & $2 / 2$ & $3 / 3$ \\
\hline Abdel Dayem et $\mathrm{al}^{8}$ & $5 / 5$ & $\mathrm{I} / 2$ & $3 / 3$ \\
\hline Cunningham et al ${ }^{9}$ & $3 / 5$ & $1 / 2$ & $2 / 3$ \\
\hline Kabali and Kabali'16 & $4 / 5$ & $2 / 2$ & $2 / 3$ \\
\hline Shalabi et al ${ }^{15}$ & $4 / 5$ & $2 / 2$ & $2 / 3$ \\
\hline Gupta et $\mathrm{al}^{7}$ & $3 / 5$ & $1 / 2$ & $2 / 3$ \\
\hline Gupta et al ${ }^{19}$ & $3 / 5$ & $1 / 2$ & $2 / 3$ \\
\hline Mourad et $\mathrm{al}^{20}$ & $4 / 5$ & $2 / 2$ & $2 / 3$ \\
\hline Al-Tahan et $\mathrm{al}^{21}$ & $3 / 5$ & $1 / 2$ & $2 / 3$ \\
\hline Kayacan et $\mathrm{al}^{14}$ & $3 / 5$ & $2 / 2$ & $2 / 3$ \\
\hline Parlewar and Shaikh" & $4 / 5$ & $2 / 2$ & $2 / 3$ \\
\hline Waseem 12 & $3 / 5$ & $2 / 2$ & $2 / 3$ \\
\hline Hafez et $\mathrm{al}^{13}$ & $3 / 5$ & $1 / 2$ & $2 / 3$ \\
\hline Parlewar and Shaikh ${ }^{17}$ & $4 / 5$ & $2 / 2$ & $2 / 3$ \\
\hline
\end{tabular}

prolonged for patients with COPD than those of controls (Figure 2). Furthermore, the interpeak latency intervals I-III of ABR waves was significantly elongated in patients with COPD than in controls (standardized mean difference $[\mathrm{SMD}]=0.27,95 \%$ CI: $0.05-0.48, P=0.02$; Figure 3 ), whereas IPLs were not significantly prolonged for both I-V and III-V peak intervals (Figure 3).

\section{Right ear}

ABR waves' latencies of the right ear were found only in seven studies. ${ }^{7,11-16}$ In spite of the relatively high heterogeneity, most peaks' absolute latencies (I, III, VI, and V) were significantly longer for patients with COPD than those of controls, and only for wave II, this increment was not statistically significant ( $P=0.12$; Figure 4$)$. Interpeak intervals of ABR waves (I-III, I-V, and III-V) showed a significant prolongation in COPD subjects compared to controls (Figure 5).

\section{Both ears}

ABR waves' latencies of both ears were found only in two studies. ${ }^{6,17} \mathrm{ABR}$ wave I latencies were significantly different between the two study groups $\left(Z=1.86, P=0.06, I^{2}=27 \%\right.$ ). However, waves III and V latencies were nonsignificantly longer for patients with COPD than the healthy controls (Figure 6).

The difference between the IPLs of ABR waves was not significantly prolonged for both waves I-III and I-V, whereas the IPLs were significantly prolonged in the patient with COPD for waves III-V (SMD $=0.51,95 \%$ CI: $0.23-0.79$, $P=0.0004$; Figure 7).

\section{PTA thresholds}

Four studies reported the mean pure tone threshold averages for both COPD and control individuals. ${ }^{5,8,9,18}$ Our findings indicated that the overall pooled mean audiometry thresholds were significantly higher in patients with COPD when compared with control cases (SMD $=1.76,95 \%$ CI: 0.43-3.08, $P=0.0004$; Figure 8 ). The pooled mean PTA thresholds at $500,1,000,2,000,4,000$, and $8,000 \mathrm{~Hz}$ for 115 subjects with COPD and 40 controls are shown in Figure 9. The highest values are obtained for 500 and 1,000 Hz. Interestingly, although the mean PTA thresholds at every frequency for COPD patients were higher than those for controls, considering the classification of the degree of $\mathrm{HL}$ of the American Speech-Language-Hearing Association, these values were still in the slight to mild HL ranges. The PTA thresholds decreased with increasing frequencies for both COPD and control groups, with SMDs being very significant at lower frequencies.

\section{Auditory P300}

Three studies provided data on mean auditory P300 latencies for both COPD and control subjects. ${ }^{19-21}$ The pooled P300 latencies were performed for 112 cases and 85 controls. We found that patients with COPD had a significantly higher latency than controls $(\mathrm{SMD}=1.30,95 \% \mathrm{CI}: 0.79-1.80$, $P=0.0001$; Figure 10).

\section{Discussion}

The current meta-analysis indicated that PTA of hearing thresholds is significantly increased in the COPD subjects than in controls. In addition, hearing thresholds were higher in COPDs at every frequency when compared with controls with increasing magnitude as the frequencies got higher. However, although the degree of HL in COPD patients was not remarkable (PTAs $<40 \mathrm{~dB} \mathrm{HL}$ ), COPD can be regarded as a risk for developing mild or subclinical hearing impairment. Abdel Dayem et $\mathrm{al}^{8}$ reported that the COPD patients have significantly higher hearing thresholds across low to high frequencies and the thresholds have markedly increased trend at high frequencies $(4,000$ and $8,000 \mathrm{~Hz})$.

It has been suggested that patients with COPD have evidence of systemic inflammation, especially when the disease is in severe phase or during exacerbations. Several inflammatory cytokines (tumor necrosis factor- $\alpha$, IL-6, CXCL8 [IL-8], and IL-18) have been implicated in the circulation of COPD patients. These cytokines are increased in sputum and bronchioalveolar lavage fluid, suggesting the role of overspill of inflammatory mediators from the lung. 


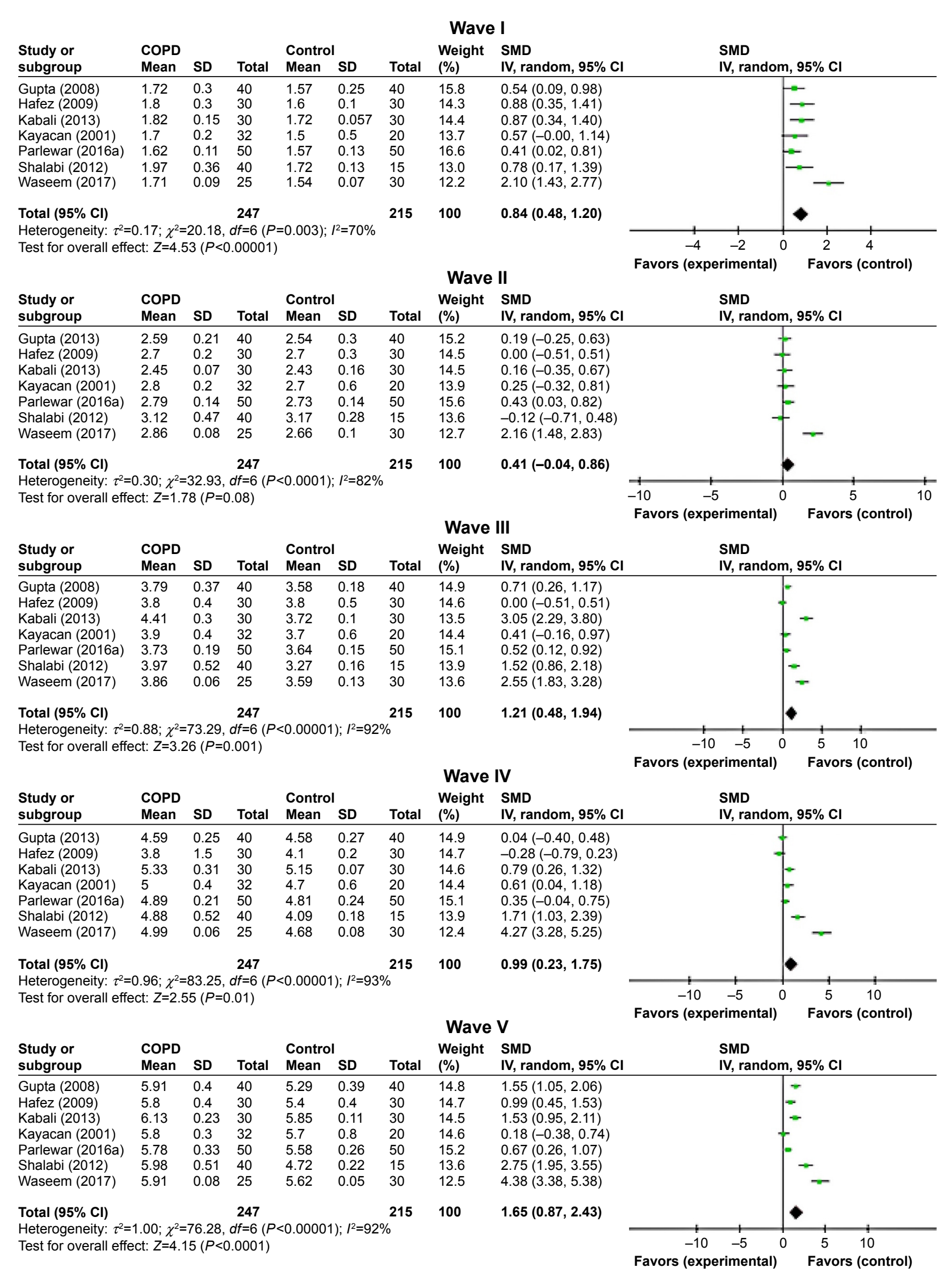

Figure 2 Forest plots of SMD for ABR waves' latencies for both COPD patients and controls.

Notes: Bars and diamonds indicate $95 \% \mathrm{Cl}$. The weights of each study in the meta-analysis are indicated. Analysis model was random effect considering high heterogeneity; effect measure was SMD.

Abbreviations: ABR, auditory brainstem-evoked responses; $d f$, degrees of freedom; IV, inverse variance; SMD, standardized mean difference. 


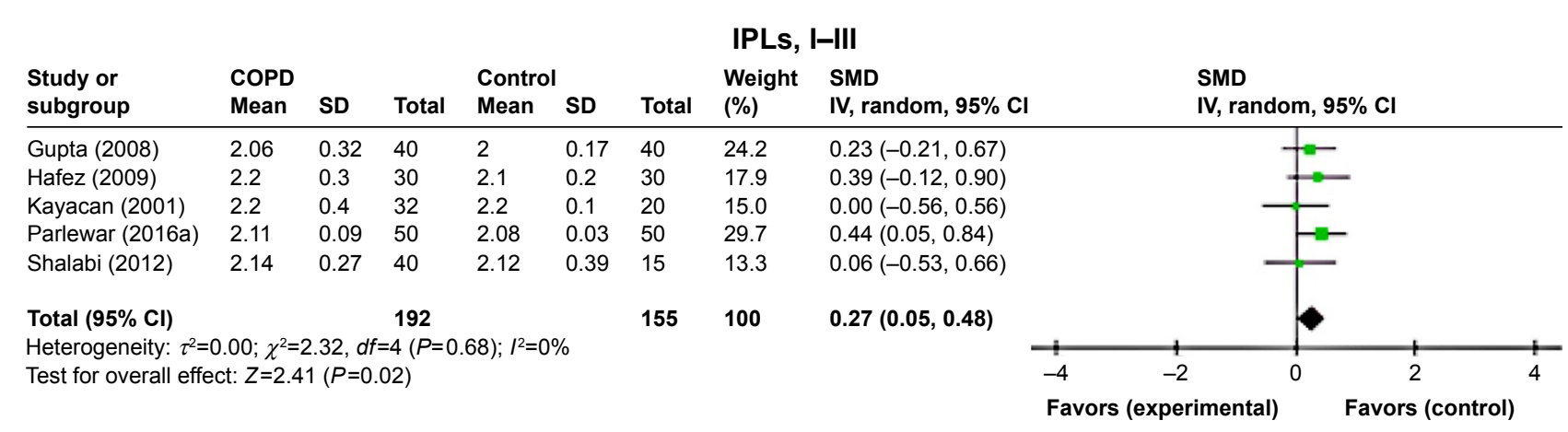

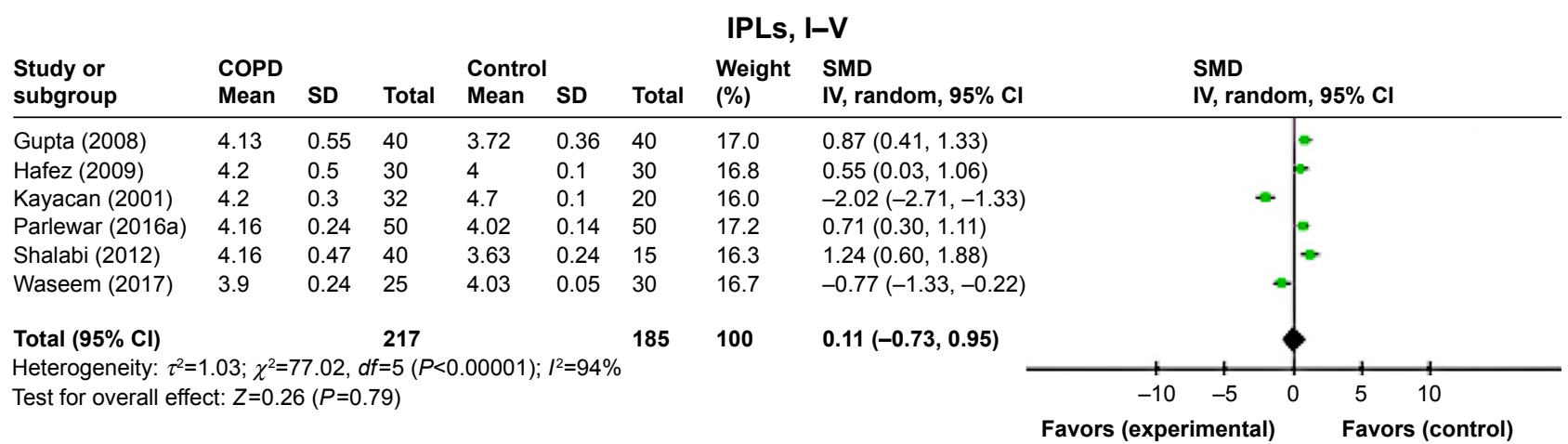

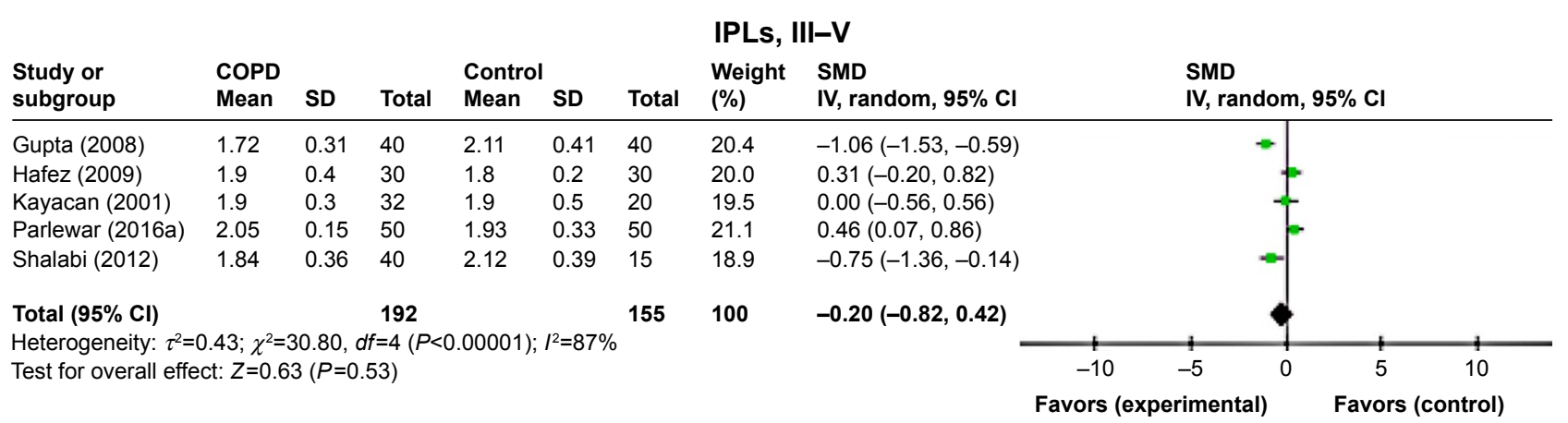

Figure 3 Forest plots of SMD for ABR waves' interpeak latencies for both COPD patients and controls.

Notes: Bars and diamonds indicate $95 \% \mathrm{Cl}$. The weights of each study in the meta-analysis are indicated. Analysis model was random effect considering high heterogeneity; effect measure was SMD.

Abbreviations: $A B R$, auditory brainstem-evoked responses; $d f$, degrees of freedom; IV, inverse variance; SMD, standardized mean difference.

The elements of this systemic inflammation may be responsible for the systemic manifestations of COPD and may worsen comorbid diseases such as HL. ${ }^{22-24}$

The transduction mechanism of the inner ear and the transmission of nerve impulses along the auditory pathway are highly dependent upon cochlear oxygen supply. ${ }^{19}$ Then, any considerable reduction in oxygen supply can affect the processes of generation and transmission of auditory nerve impulses at the level of the auditory system and leads to hearing impairment. ${ }^{7}$ A decrement in the availability of oxygen to the cochlea also has a marked effect on the cochlear potentials, including endolymphatic potential. Johnstone and Sellick ${ }^{25}$ explained the reduction in auditory sensitivity via a decrease of endolymphatic potential; this potential contributes to the extraordinary high sensitivity of the mammalian cochlea. However, Kamenski et al's ${ }^{18}$ findings do not support the hypothesis that there is a clinically relevant difference in the hearing performance of patients with COPD which is assessed by PTA.

Our study showed that COPD is associated with a specific damage to the auditory brainstem function. Analyses of ABR wave latencies and interpeak latencies with pooled data analyses revealed significantly longer wave latencies in patients with COPD than in controls. The ABR wave latencies provide information on how fast electrical sound signals are transmitted through various parts of the auditory brainstem. Hence, the elongation of these latencies would suggest that there is a delay in the conduction of auditory signals. These outcomes supported that COPD might be a cause of certain dysfunctions of the central and peripheral 
auditory pathways. Neuronal involvement is common among chronic respiratory complications. It is, therefore, not surprising that neurons at the brainstem level would show remarkable alternations with the COPD disorder.
Atis et $\mathrm{al}^{6}$ reported a high rate of $\mathrm{ABR}$ abnormalities (76.1\%) in patients with severe COPD. In their study, the most prominent ABR abnormalities were prolonged wave I peak latencies and low wave I peak amplitude, which represent

\begin{tabular}{|c|c|c|c|c|c|c|c|c|}
\hline \multirow[b]{2}{*}{$\begin{array}{l}\text { Study or } \\
\text { subgroup }\end{array}$} & \multirow[b]{2}{*}{$\begin{array}{l}\text { COPD } \\
\text { Mean }\end{array}$} & \multirow[b]{2}{*}{ SD } & \multirow[b]{2}{*}{ Total } & \multirow[b]{2}{*}{$\begin{array}{l}\text { Control } \\
\text { Mean }\end{array}$} & \multicolumn{4}{|c|}{ Wave I } \\
\hline & & & & & SD & Total & $\begin{array}{l}\text { Weight } \\
(\%)\end{array}$ & $\begin{array}{l}\text { SMD } \\
\text { IV, random, } 95 \% \mathrm{CI}\end{array}$ \\
\hline Gupta (2008) & 1.43 & 0.18 & 40 & 1.41 & 0.1 & 40 & 15.1 & $0.14(-0.30,0.57)$ \\
\hline Hafez (2009) & 1.9 & 0.4 & 30 & 1.6 & 0.15 & 30 & 14.3 & $0.98(0.44,1.52)$ \\
\hline Kabali (2013) & 1.86 & 0.11 & 30 & 1.8 & 0.09 & 30 & 14.5 & $0.59(0.07,1.11)$ \\
\hline Kayacan (2001) & 1.6 & 0.2 & 32 & 1.7 & 0.4 & 20 & 14.2 & $-0.34(-0.90,0.23)$ \\
\hline Parlewar (2016a) & 1.62 & 0.1 & 50 & 1.56 & 0.12 & 50 & 15.3 & $0.54(0.14,0.94)$ \\
\hline Shalabi (2012) & 1.73 & 0.41 & 40 & 1.42 & 0.13 & 15 & 13.7 & $0.85(0.24,1.47)$ \\
\hline Waseem (2017) & 1.72 & 0.09 & 25 & 1.54 & 0.05 & 30 & 12.9 & $2.50(1.78,3.22)$ \\
\hline Total $(95 \% \mathrm{Cl})$ & & & 247 & & & 215 & 100 & $0.72(0.18,1.26)$ \\
\hline
\end{tabular}

Test for overall effect: $Z=2.62(P=0.009)$

Wave II

\begin{tabular}{lllllllll}
$\begin{array}{l}\text { Study or } \\
\text { subgroup }\end{array}$ & $\begin{array}{l}\text { COPD } \\
\text { Mean }\end{array}$ & SD & Total & $\begin{array}{l}\text { Control } \\
\text { Mean }\end{array}$ & SD & Total & $\begin{array}{l}\text { Weight } \\
(\%)\end{array}$ & $\begin{array}{l}\text { SMD } \\
\text { IV, random, 95\% CI }\end{array}$ \\
\hline Gupta (2008) & 2.81 & 0.21 & 40 & 2.47 & 0.21 & 40 & 14.5 & $1.60(1.10,2.11)$ \\
Hafez (2009) & 2.6 & 0.3 & 30 & 2.5 & 0.3 & 30 & 14.4 & $0.33(-0.18,0.84)$ \\
Kabali (2013) & 2.74 & 0.23 & 30 & 2.71 & 0.07 & 30 & 14.5 & $0.17(-0.33,0.68)$ \\
Kayacan (2001) & 2.6 & 0.4 & 32 & 2.7 & 0.5 & 20 & 14.2 & $-0.22(-0.78,0.34)$ \\
Parlewar (2016a) & 2.79 & 0.16 & 50 & 2.75 & 0.12 & 50 & 15.0 & $0.28(-0.11,0.67)$ \\
Shalabi (2012) & 2.9 & 0.46 & 40 & 3.17 & 0.28 & 15 & 13.9 & $-0.63(-1.24,-0.03)$ \\
Waseem (2017) & 2.89 & 0.1 & 25 & 2.68 & 0.09 & 30 & 13.5 & $2.19(1.51,2.87)$ \\
& & & & & & & & \\
Total (95\% Cl) & & & $\mathbf{2 4 7}$ & & & $\mathbf{2 1 5}$ & $\mathbf{1 0 0}$ & $\mathbf{0 . 5 2}(-\mathbf{0 . 1 3}, \mathbf{1 . 1 7})$
\end{tabular}

Heterogeneity: $\tau^{2}=0.70 ; \chi^{2}=64.85, d f=6(P<0.00001) ; I^{2}=91 \%$

Test for overall effect: $Z=1.57(P=0.12)$

\begin{tabular}{|c|c|c|c|c|c|c|c|c|}
\hline \multirow[b]{2}{*}{$\begin{array}{l}\text { Study or } \\
\text { subgroup }\end{array}$} & \multirow[b]{2}{*}{$\begin{array}{l}\text { COPD } \\
\text { Mean }\end{array}$} & \multirow[b]{2}{*}{ SD } & \multirow[b]{2}{*}{ Total } & \multirow[b]{2}{*}{$\begin{array}{l}\text { Control } \\
\text { Mean }\end{array}$} & \multirow[b]{2}{*}{ SD } & \multicolumn{3}{|c|}{ Wave III } \\
\hline & & & & & & Total & $\begin{array}{l}\text { Weight } \\
(\%)\end{array}$ & $\begin{array}{l}\text { SMD } \\
\text { IV, fixed, } 95 \% \mathrm{CI}\end{array}$ \\
\hline Gupta (2008) & 3.73 & 0.38 & 40 & 3.36 & 0.14 & 40 & 17.2 & $1.28(0.80,1.76)$ \\
\hline Hafez (2009) & 3.73 & 0.38 & 40 & 3.36 & 0.14 & 40 & 17.2 & $1.28(0.80,1.76)$ \\
\hline Kabali (2013) & 3.74 & 0.08 & 30 & 3.7 & 0.08 & 30 & 15.2 & $0.49(-0.02,1.01)$ \\
\hline Kayacan (2001) & 3.9 & 0.4 & 32 & 3.9 & 0.4 & 20 & 12.8 & $0.00(-0.56,0.56)$ \\
\hline Parlewar (2016a) & 3.74 & 0.15 & 50 & 3.65 & 0.17 & 50 & 25.1 & $0.56(0.16,0.96)$ \\
\hline Shalabi (2012) & 4.21 & 0.54 & 40 & 3.37 & 0.16 & 15 & 8.6 & $1.76(1.08,2.44)$ \\
\hline Waseem (2017) & 3.88 & 0.06 & 25 & 3.59 & 0.07 & 30 & 4.0 & $4.35(3.36,5.35)$ \\
\hline Total $(95 \% \mathrm{Cl})$ & & & 257 & & & 225 & 100 & $0.98(0.78,1.18)$ \\
\hline
\end{tabular}

Heterogeneity: $\chi^{2}=71.46, d f=6(P<0.00001) ; l^{2}=92 \%$

Test for overall effect: $Z=9.59(P<0.00001)$

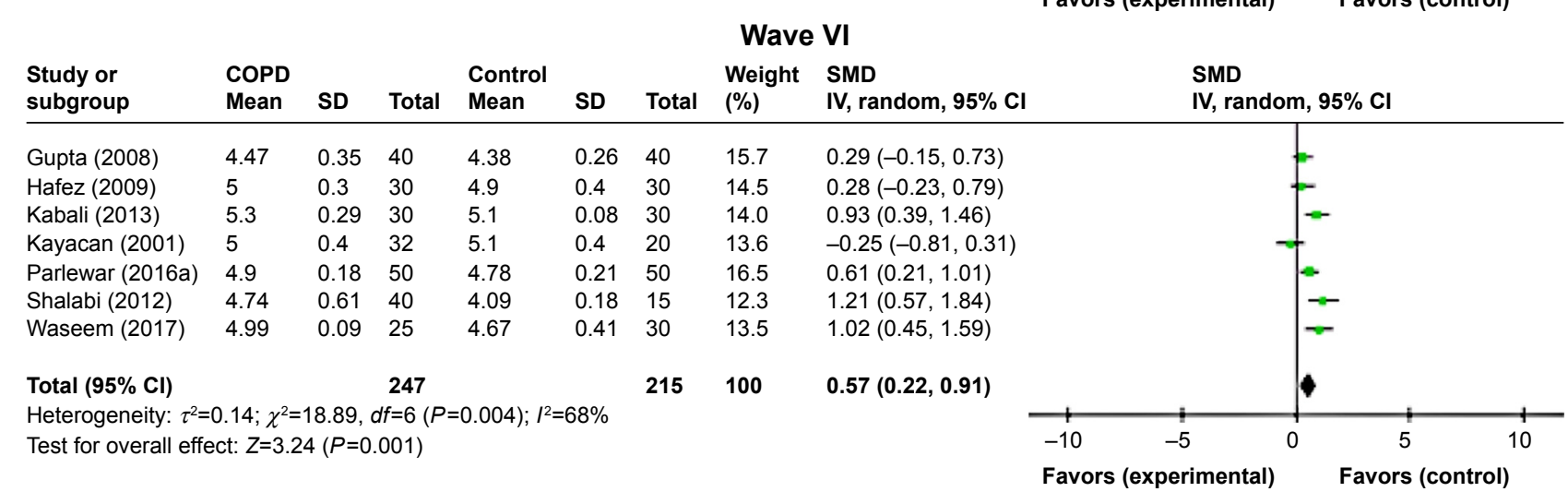

Wave VI

Figure 4 (Continued) 


\begin{tabular}{|c|c|c|c|c|c|c|c|c|c|c|c|c|}
\hline \multirow{3}{*}{$\begin{array}{l}\begin{array}{l}\text { Study or } \\
\text { subgroup }\end{array} \\
\text { Gupta (2008) }\end{array}$} & \multirow{3}{*}{$\begin{array}{l}\begin{array}{l}\text { COPD } \\
\text { Mean }\end{array} \\
5.85\end{array}$} & \multirow{3}{*}{$\begin{array}{l}\text { SD } \\
0.36\end{array}$} & \multirow{3}{*}{$\begin{array}{l}\text { Total } \\
40\end{array}$} & \multirow{3}{*}{$\begin{array}{l}\begin{array}{l}\text { Control } \\
\text { Mean }\end{array} \\
5.27\end{array}$} & \multirow{3}{*}{$\frac{S D}{0.21}$} & \multicolumn{3}{|c|}{ Wave V } & \multirow{2}{*}{\multicolumn{3}{|c|}{$\begin{array}{l}\text { SMD } \\
\text { IV, random, } 95 \% \mathrm{CI}\end{array}$}} & \\
\hline & & & & & & Total & $\begin{array}{l}\text { Weight } \\
(\%)\end{array}$ & $\begin{array}{l}\text { SMD } \\
\text { IV, random, } 95 \% \mathrm{CI}\end{array}$ & & & & \\
\hline & & & & & & 40 & 14.6 & $1.95(1.41,2.49)$ & & & \multicolumn{2}{|l|}{. } \\
\hline Hafez (2009) & 5.4 & 0.4 & 30 & 5.2 & 0.3 & 30 & 14.6 & $0.56(0.04,1.07)$ & & & \multirow{3}{*}{ 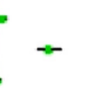 } & \\
\hline Kabali (2013) & 6.8 & 0.23 & 30 & 5.72 & 0.11 & 30 & 13.1 & $5.91(4.71,7.12)$ & & & & \\
\hline Kayacan (2001) & 5.8 & 0.4 & 32 & 5.8 & 0.5 & 20 & 14.6 & $0.00(-0.56,0.56)$ & & & & \\
\hline Parlewar (2016a) & 5.72 & 0.29 & 50 & 5.61 & 0.3 & 50 & 14.8 & $0.37(-0.03,0.77)$ & & & & \\
\hline Shalabi (2012) & 6 & 0.59 & 40 & 4.72 & 0.22 & 15 & 14.2 & $2.43(1.67,3.19)$ & & & * & \\
\hline Waseem (2017) & 5.95 & 0.07 & 50 & 5.63 & 0.07 & 30 & 14.0 & $4.53(3.68,5.38)$ & & & $=$ & \\
\hline \multicolumn{3}{|l|}{ Total $(95 \% \mathrm{Cl})$} & 272 & & & 215 & 100 & $2.18(0.94,3.42)$ & & & \multicolumn{2}{|l|}{1} \\
\hline \multirow{2}{*}{\multicolumn{9}{|c|}{ Heterogeneity: $\tau^{2}=2.66 ; \chi^{2}=175.57, d f=6(P<0.00001) ; l^{2}=97 \%$}} & & & $i$ & \\
\hline & & & & & & & & & -20 & -10 & 10 & 20 \\
\hline & & & & & & & & & ors (ex & rime & \multicolumn{2}{|c|}{ Favors (control) } \\
\hline
\end{tabular}

Figure 4 Forest plots of SMD for ABR waves' latencies for both COPD patients and controls.

Notes: Bars and diamonds indicate $95 \% \mathrm{Cl}$. The weights of each study in the meta-analysis are indicated. Analysis model was random effect considering high heterogeneity; effect measure was SMD.

Abbreviations: ABR, auditory brainstem-evoked responses; df, degrees of freedom; IV, inverse variance; SMD, standardized mean difference.

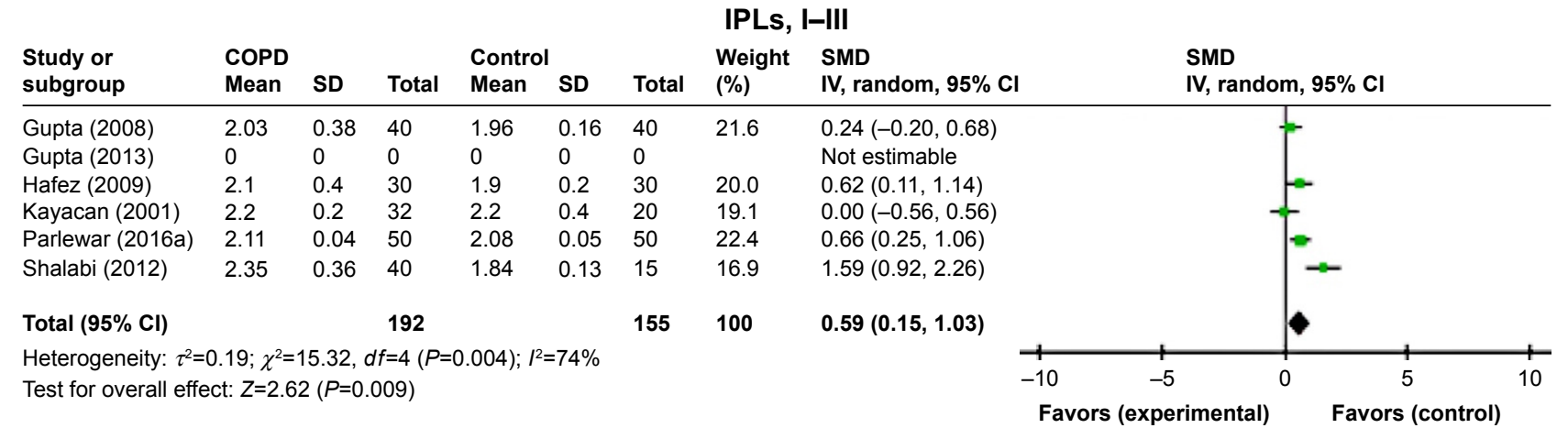

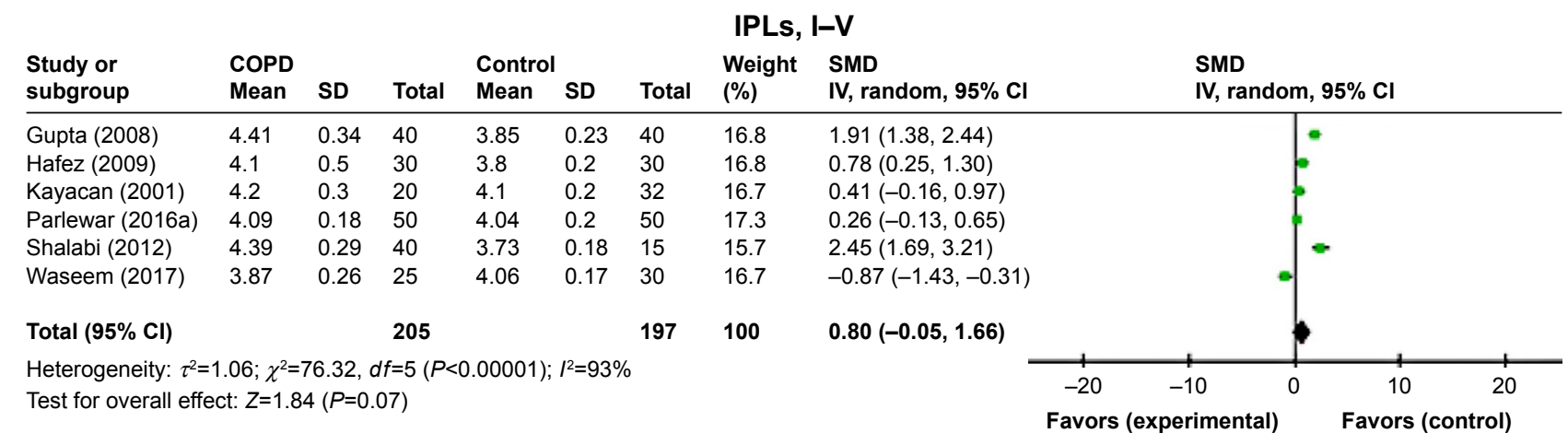

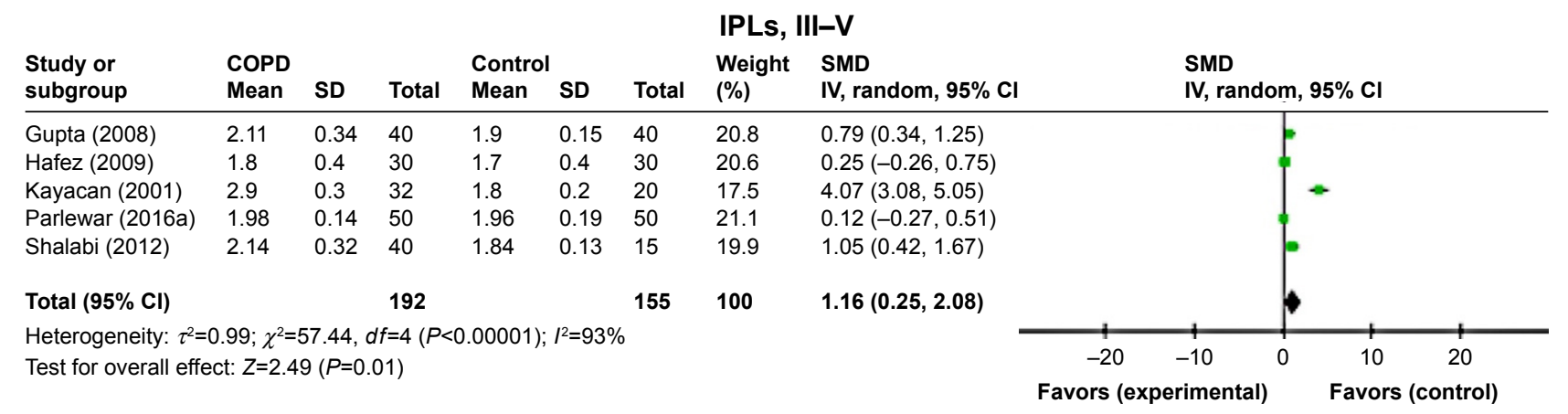

Figure 5 Forest plots of SMD for ABR waves' interpeak latencies for both COPD patients and controls.

Notes: Bars and diamonds indicate $95 \% \mathrm{Cl}$. The weights of each study in the meta-analysis are indicated. Analysis model was random effect considering high heterogeneity; effect measure was SMD.

Abbreviations: ABR, auditory brainstem-evoked responses; $d f$, degrees of freedom; IV, inverse variance; SMD, standardized mean difference. 


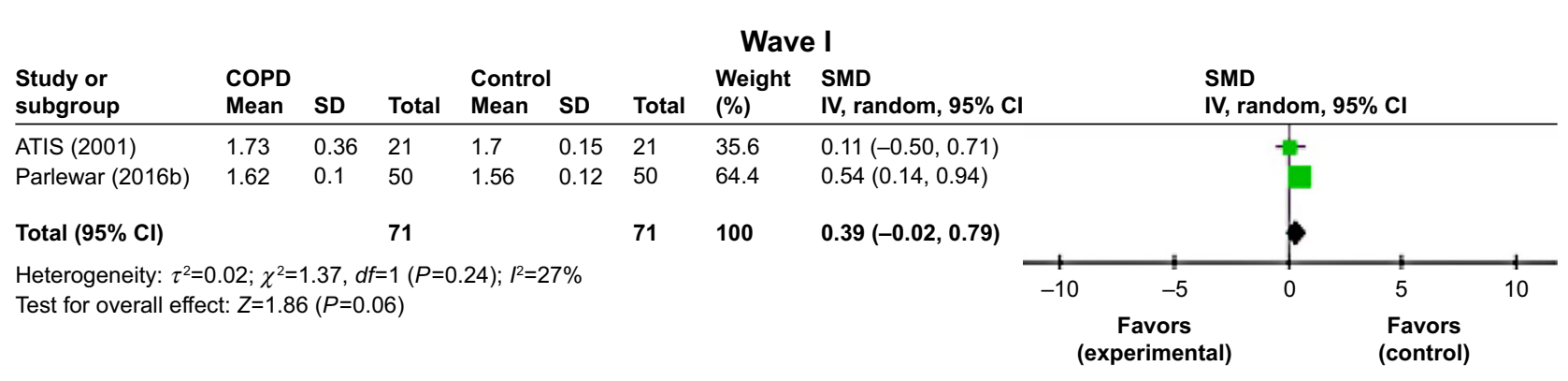

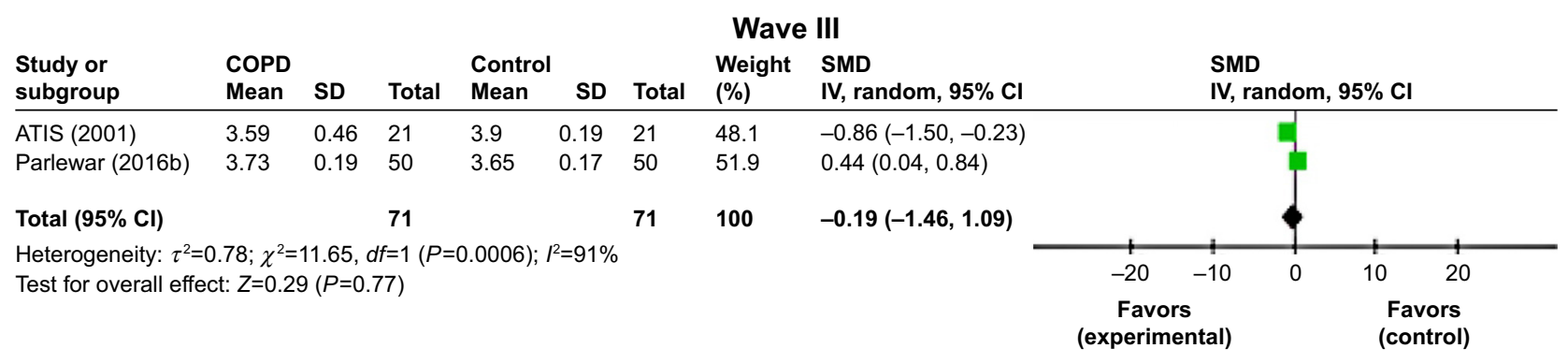

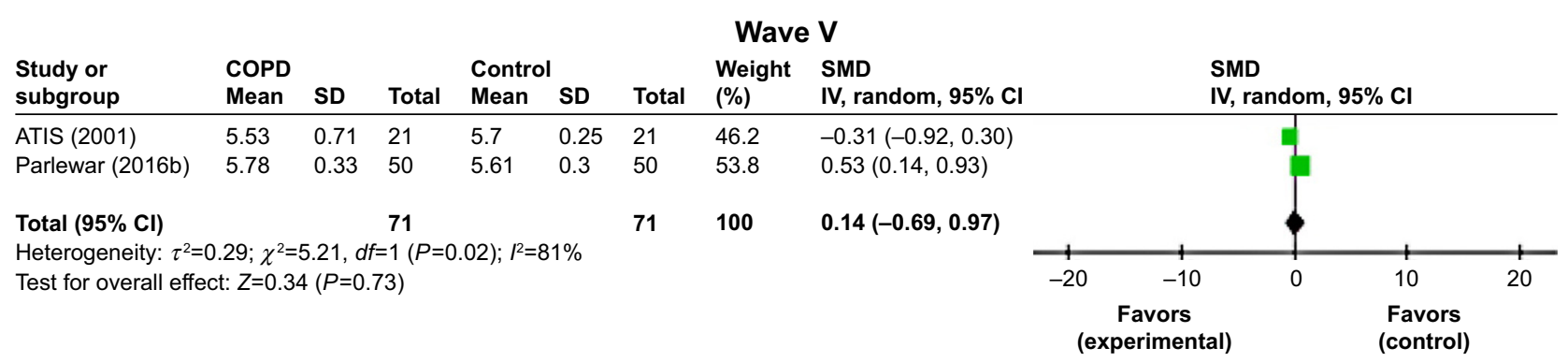

Figure 6 Forest plots of SMD for ABR waves' latencies for both COPD patients and controls.

Notes: Bars and diamonds indicate $95 \% \mathrm{Cl}$. The weights of each study in the meta-analysis are indicated. Analysis model was random effect considering high heterogeneity; effect measure was SMD.

Abbreviations: ABR, auditory brainstem-evoked responses; $d f$, degrees of freedom; IV, inverse variance; SMD, standardized mean difference.

the function of eight cranial nerves (peripheral component of the auditory system). No significant correlation was found between ABR abnormalities and results of spirometric and arterial blood gas parameters (eg, hematocrit, $\mathrm{PaCO}_{2}, \mathrm{FEV}_{1} \%$, $\left.\mathrm{pH}, \mathrm{PaO}_{2}, \mathrm{FEV}_{1} / \mathrm{FVC}\right)$ in COPD patients. Gupta et al's findings demonstrated that $65 \%(26 / 40)$ of COPD subjects had abnormal ABRs, which were more common in the form of prolonged absolute peak latencies (waves I, III, and V) and interpeak intervals (I-III and III-V) in both sides. They also found no correlation or poor correlation between ABR abnormalities and pulmonary function test parameters. In contrast to Gupta et $\mathrm{al}^{7}$ and Atis et al' $\mathrm{s}^{6}$ investigations, Nakano et $\mathrm{al}^{26}$ and Barbieri et al's ${ }^{27}$ studies revealed no significant differences in ABR parameters between patients with chronic respiratory insufficiency and controls.

COPD has been found to cause a general cognitive decline such as attention, psychomotor speed, memory and learning, visuospatial skill, and auditory perception. ${ }^{28-30}$ Analyses of auditory P300 latency with pooled data analyses revealed significantly prolonged latencies for COPD patients than controls. The auditory P300 potential is reflective of sensory and cognitive functions. P300 is related to the activity of associative cortical areas and represents conscious recognition, auditory information recognition and memory context updating. ${ }^{30-32} \mathrm{P} 300$ latency can be used as a marker of cognitive performance (central processing time), and its delay has already been suggested in different metabolic encephalopathies. ${ }^{33} \mathrm{Al}$-Tahan et $\mathrm{al}^{21}$ observed that auditory evoked potential latencies, particularly those of P300, were significantly prolonged in patients with chronic respiratory difficulty, in spite of a majority of cases having normal mental state examination (78\%). These findings indicate that subclinical cognitive dysfunction (encephalopathy) is common in this group of patients.

The underlying mechanisms of cognitive impairments in COPD remain a controversial issue. Hypoxemia, hypercapnia, or vascular comorbidities have been proposed as possible causes of brain alterations in patients 


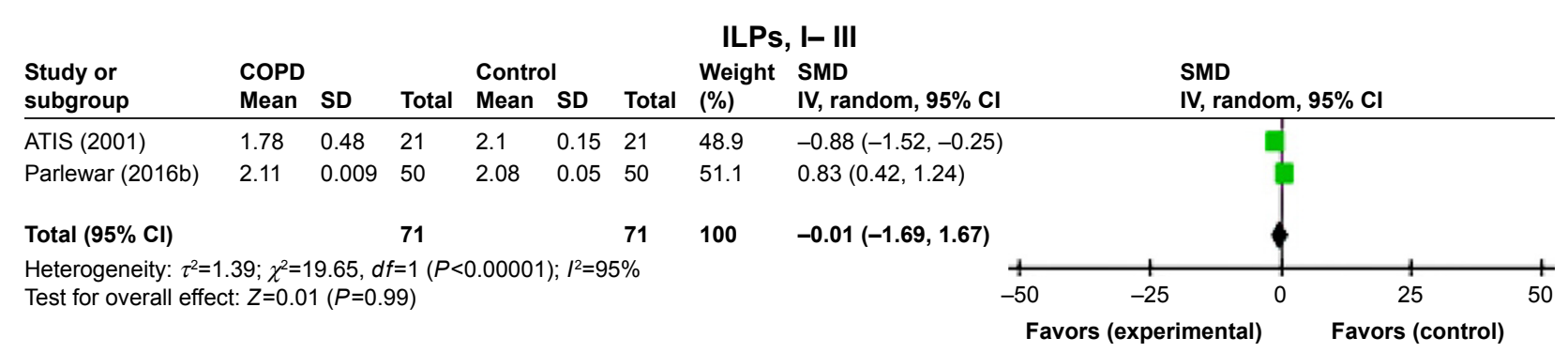

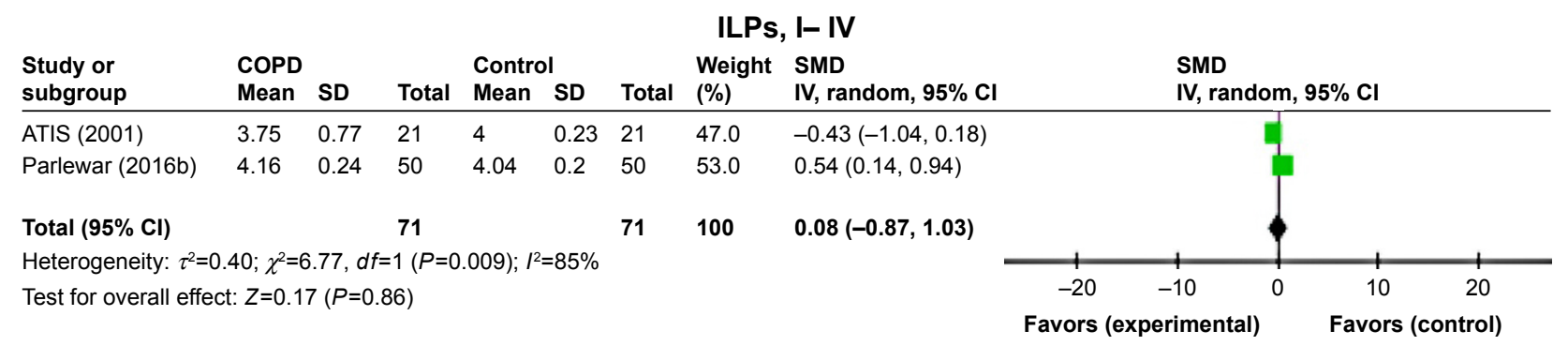

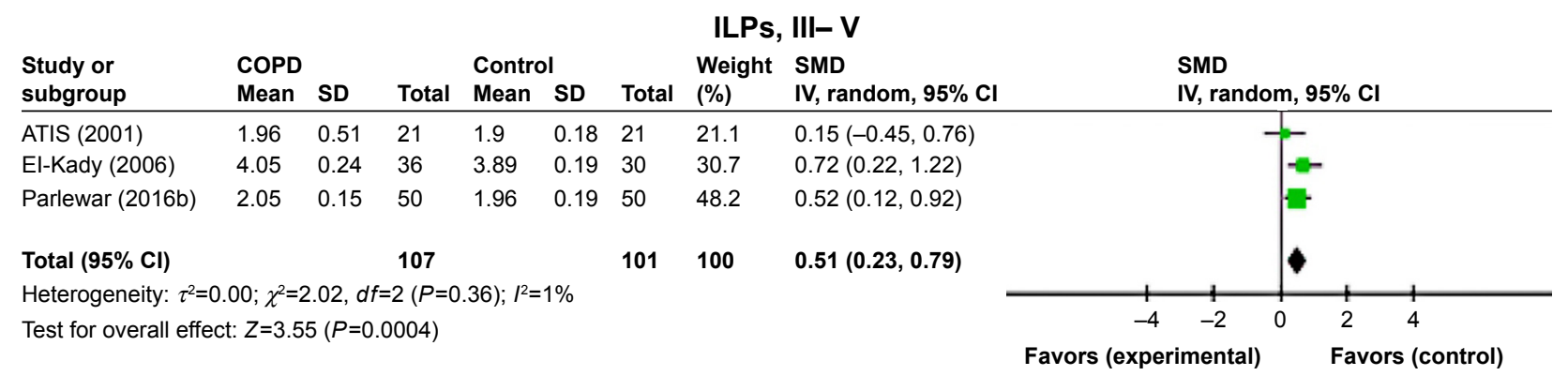

Figure 7 Forest plots of SMD for ABR waves' interpeak latencies for both COPD patients and controls.

Notes: Bars and diamonds indicate $95 \% \mathrm{Cl}$. The weights of each study in the meta-analysis are indicated. Analysis model was random effect considering high heterogeneity; effect measure was SMD.

Abbreviations: ABR, auditory brainstem-evoked responses; $d f$, degrees of freedom; IV, inverse variance; SMD, standardized mean difference.

with COPD. ${ }^{34,35}$ Ortapamuk and Naldoken ${ }^{4}$ reported that individuals with severe COPD may develop changes in brain perfusion due to hypoxemia, leading to cognitive impairment. In an experimental design, Guo et $\mathrm{al}^{36}$ suggested that chronic asthma affects synaptic structure and long-term potentiation, and neurogenesis induced by intermittent hypoxia during the disease course might contribute to higher cognitive (language, learning, and memory) dysfunctions.

Our results indicated that there is some heterogeneity (a high $I^{2}$ value of $>80 \%$ ) in the findings of the involved articles, which may be attributed to many differences in the studies included. This can be due to disparities in the

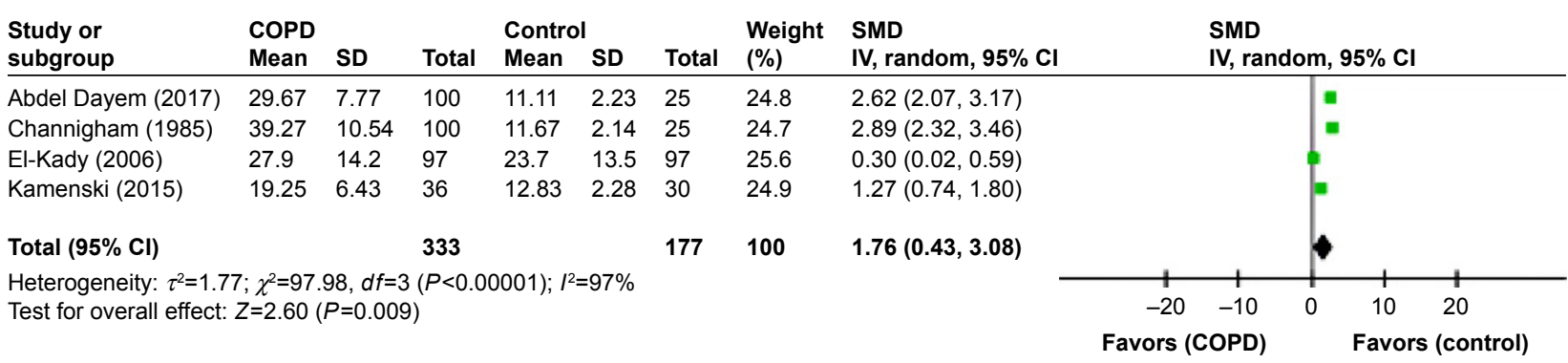

Figure 8 Forest plots of studies showing overall SMD for PTA thresholds in patients with COPD and controls at various frequencies.

Notes: Bars and diamonds indicate $95 \% \mathrm{Cls}$. The weights of each study in the meta-analysis are indicated. Analysis model, random effect; effect measure is mean difference. Abbreviations: $d f$, degrees of freedom; IV, inverse variance; PTA, pure tone audiometry; SMD, standardized mean difference. 


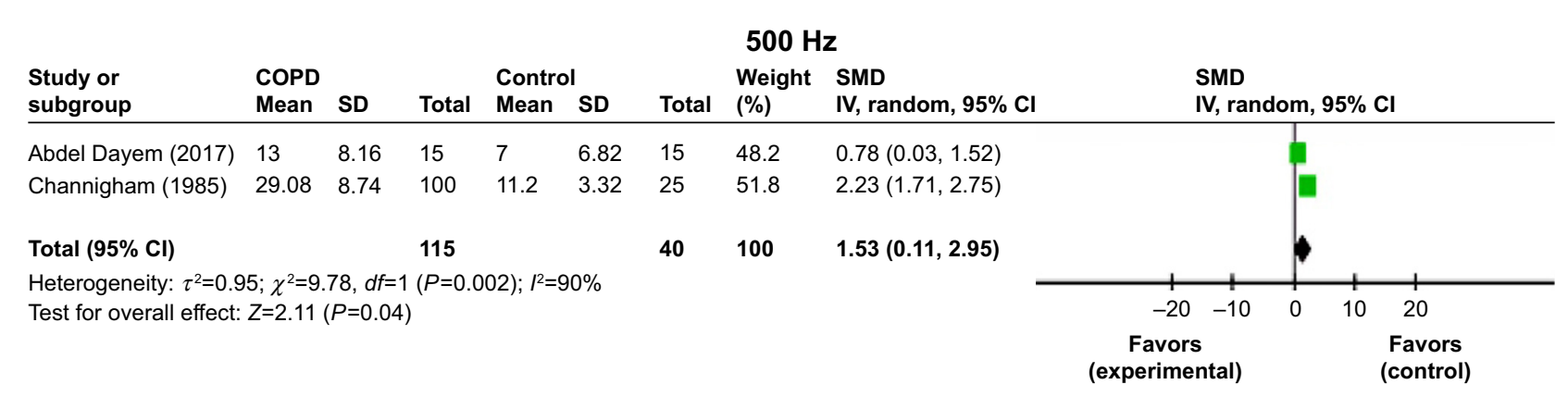

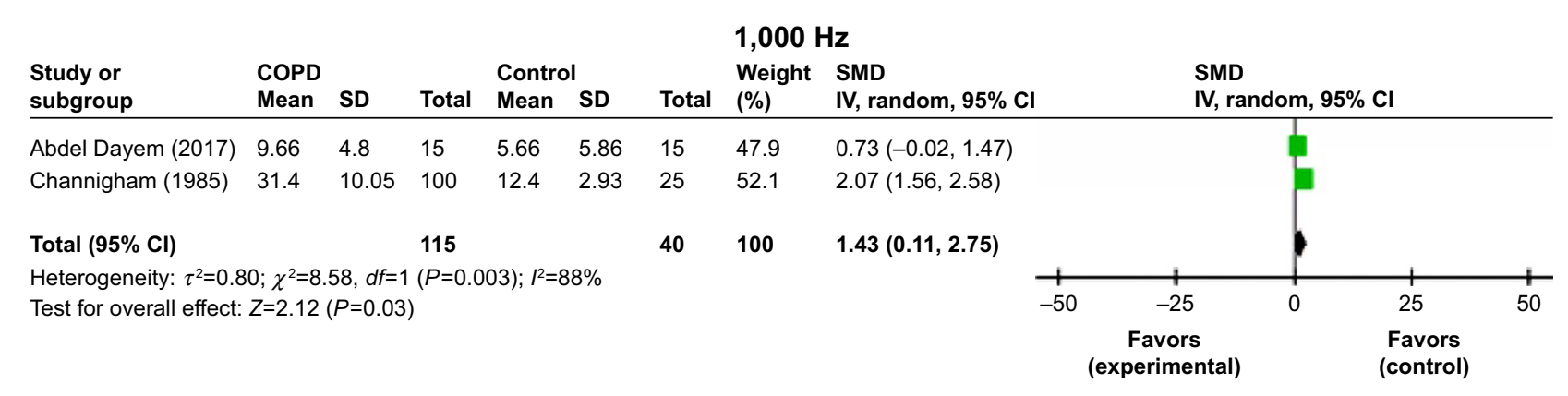

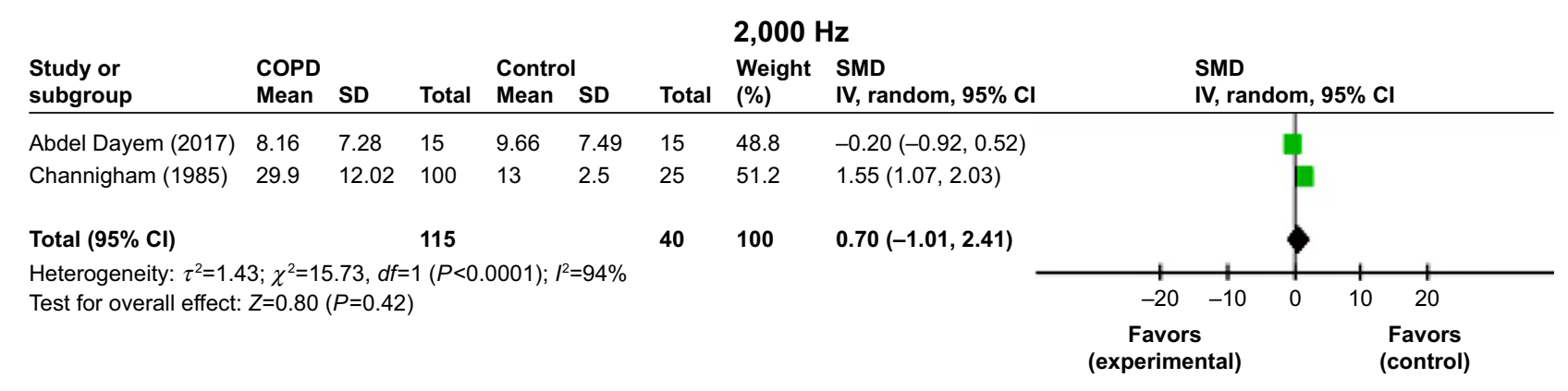

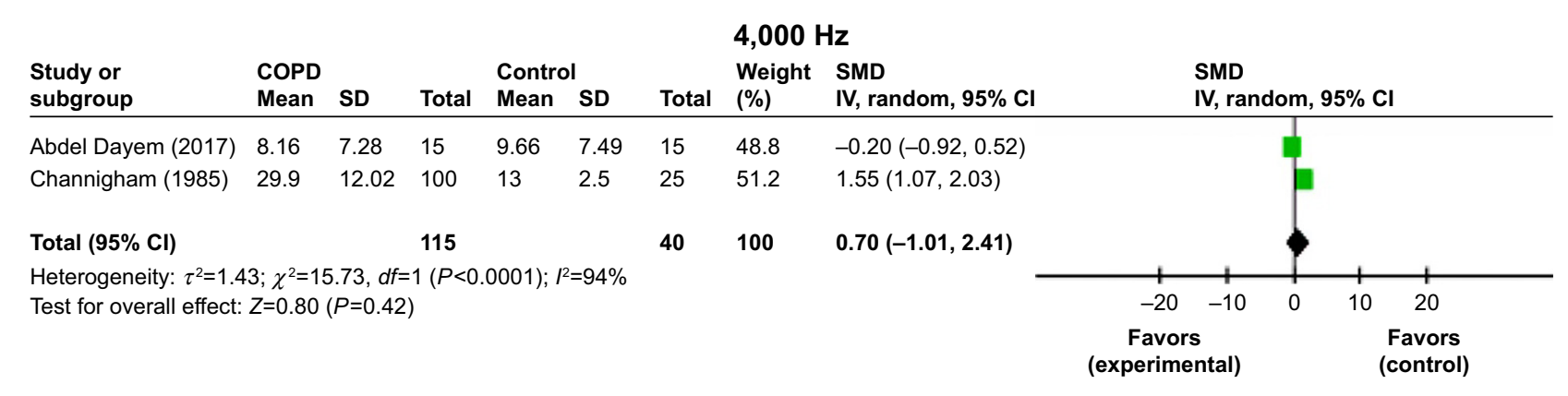

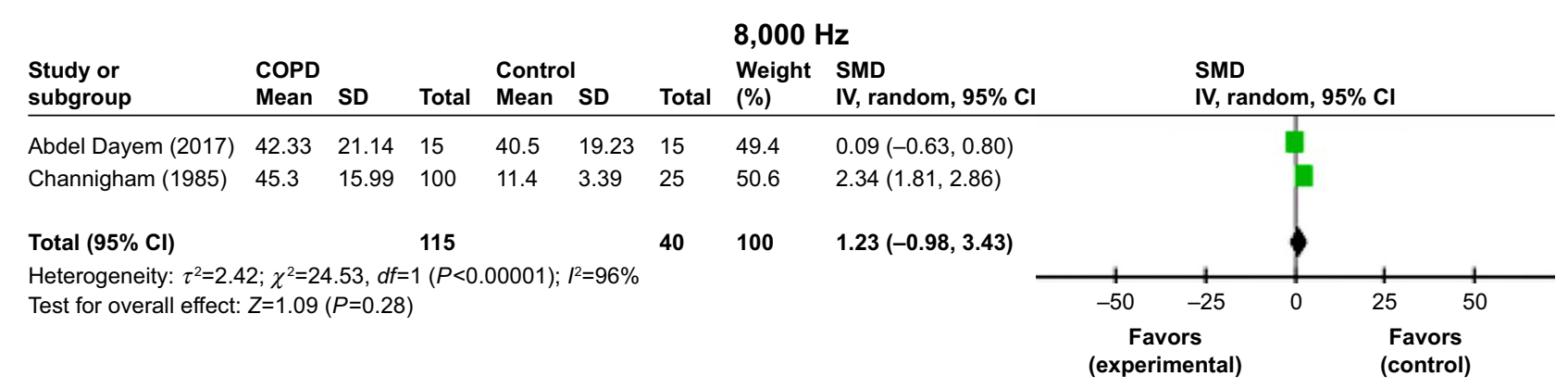

Figure 9 Forest plots of studies showing overall SMD for PTA thresholds in patients with COPD and controls at 500, I,000, 4,000, 6,000, and 8,000 Hz. Bars and diamonds indicate $95 \%$ Cls.

Notes: The weights of each study in the meta-analysis are indicated. Analysis model, random effect; effect measure is mean difference.

Abbreviations: $d f$, degrees of freedom; IV, inverse variance; PTA, pure tone audiometry; SMD, standardized mean difference. 


\begin{tabular}{|c|c|c|c|c|c|c|c|}
\hline $\begin{array}{l}\text { Study or } \\
\text { subgroup }\end{array}$ & $\begin{array}{l}\text { COPD } \\
\text { Mean }\end{array}$ & SD & Total & $\begin{array}{l}\text { Control } \\
\text { Mean }\end{array}$ & SD & Total & $\begin{array}{l}\text { Weight } \\
(\%)\end{array}$ \\
\hline Al-Tahan (2002) & 435.28 & 64.6 & 32 & 366.18 & 62.1 & 25 & 32.8 \\
\hline Gupta (2013) & 300.06 & 22.57 & 40 & 265.19 & 15.49 & 40 & 34.7 \\
\hline Mourad (2017) & 324.25 & 21.91 & 40 & 305.13 & 10.27 & 20 & 32.5 \\
\hline \multicolumn{3}{|l|}{ Total $(95 \% \mathrm{Cl})$} & 112 & & & 85 & 100 \\
\hline \multicolumn{8}{|c|}{ Heterogeneity: $\tau^{2}=0.12 ; \chi^{2}=5.01, d f=2(P=0.08) ; I^{2}=60 \%$} \\
\hline
\end{tabular}

Figure 10 Comparison of P300 latency between COPD and control groups. Abbreviation: $d f$, degrees of freedom.

sample sizes, dissimilarities in population, difference in the proportions of COPD to control contributors, and variations in $\mathrm{HL}$ incidence.

\section{Limitations}

There are a few limitations that could be potential sources of bias in this meta-analysis (Supplementary material). First, our analysis is based on the findings of observational studies; therefore, it is impossible to control residual confounders linking COPDs and hearing impairment. Second, it seems that the duration and severity of COPD can influence the strength of the association between disease and HL and produce between-study heterogeneity in the association, but there is not enough information regarding duration and severity of COPD in the included studies. Third, publication bias is inevitable because researchers are not as likely to report negative results. Its possibility could not be ruled out even if it were not statistically derived.

\section{Conclusion}

COPD patients had considerably greater incidence of HL when compared with controls. Interestingly, although the mean PTA thresholds at every frequency for COPD patients were higher than those for controls, these values were still in the slight to mild HL ranges. Prolonged ABR wave latencies in the COPD patients suggest retro-cochlear involvement. Thus, COPD most frequently clusters with HL, but it is worth noting that alteration in hearing is not always recognized by medical experts as a frequent comorbidity associated with COPD.

\section{Disclosure}

The authors report no conflicts of interest in this work.

\section{References}

1. Kukrety SP, Parekh JD, Bailey KL. Chronic obstructive pulmonary disease and the hallmarks of aging. Lung India. 2018;35(4):321-327.
2. Wilkinson TM, Donaldson GC, Hurst JR, Seemungal TA, Wedzicha JA. Early therapy improves outcomes of exacerbations of chronic obstructive pulmonary disease. Am J Respir Crit Care Med. 2004;169(12): 1298-1303.

3. Schou L, Østergaard B, Rasmussen LS, Rydahl-Hansen S, Phanareth K. Cognitive dysfunction in patients with chronic obstructive pulmonary disease - a systematic review. Respir Med. 2012;106(8):1071-1081.

4. Ortapamuk H, Naldoken S. Brain perfusion abnormalities in chronic obstructive pulmonary disease: comparison with cognitive impairment. Ann Nucl Med. 2006;20(2):99-106.

5. El-Kady MA, Durrant JD, Tawfik S, Abdel-Ghany S, Moussa AM. Study of auditory function in patients with chronic obstructive pulmonary diseases. Hear Res. 2006;212(1-2):109-116.

6. Atiş S, Ozge A, Sevim S. The brainstem auditory evoked potential abnormalities in severe chronic obstructive pulmonary disease. Respirology. 2001;6(3):225-229.

7. Gupta PP, Sood S, Atreja A, Agarwal D. Evaluation of brain stem auditory evoked potentials in stable patients with chronic obstructive pulmonary disease. Ann Thorac Med. 2008;3(4):128-134.

8. Abdel Dayem AM, Galal IH, Naeem F, Hassan MA. Audiological assessment in patients with chronic obstructive pulmonary disease. Egypt J Bronchol. 2017:11:98-103.

9. Cunningham DR, Cunningham CA, Vise LK. The effects of chronic hypoxemia on central auditory processing in patients with chronic obstructive pulmonary disease. Ear Hear. 1985;6(6):297-303.

10. van Dinteren R, Arns M, Jongsma ML, Kessels RP. P300 development across the lifespan: a systematic review and meta-analysis. PLoS One. 2014;9(2):e87347.

11. Parlewar R, Shaikh R. Correlation of disease duration, smoking pack years and FEV1\% predicted with BAEP parameters in patients of COPD. Int J Curr Res Rev. 2016;8(1):9.

12. Waseem SMA. Smoking-induced oxidant/antioxidant imbalance in chronic obstructive pulmonary disease: assessment of auditory evoked potential: a comparative study of smokers and non-smokers with or without chronic obstructive pulmonary disease. Nat J Physiol Pharm Pharmacol. 2018;8(2):152-157.

13. Hafez MR, Maabady MH, Aboelkheir OI, Elsheikh RM. Chronic obstructive pulmonary disease and its relation to impairment of visual and brainstem auditory evoked potentials. AAMJ. 2009;7(3): $22-46$.

14. Kayacan O, Beder S, Deda G, Karnak D. Neurophysiological changes in COPD patients with chronic respiratory insufficiency. Acta Neurol Belg. 2001;101(3):160-165.

15. Shalabi N, El-Salam MA, Abbas F. Brain-stem auditory evoked responses in COPD patients. Egypt J Chest Dis Tuberc. 2012;61(4):313-321.

16. Kabali S, Kabali B. Brainstem auditory evoked potential changes in chronic obstructive pulmonary disease individuals. World J Med Sci. 2013;8(3):195-198.

17. Parlewar R, Shaikh R. Evaluation of latencies and interpeak latencies of BAEP waves in COPD patients. Indian J Physiol Pharmacol. 2016;60(2):128-136. 
18. Kamenski G, Bendova J, Fink W, Sönnichsen A, Spiegel W, Zehetmayer S. Does COPD have a clinically relevant impact on hearing loss? A retrospective matched cohort study with selection of patients diagnosed with COPD. BMJ Open. 2015;5(11):e008247.

19. Gupta PP, Sood S, Atreja A, Agarwal D. A comparison of cognitive functions in non-hypoxemic chronic obstructive pulmonary disease (COPD) patients and age-matched healthy volunteers using minimental state examination questionnaire and event-related potential, P300 analysis. Lung India. 2013;30(1):5-11.

20. Mourad S, Abd Al-Ghaffar M, Abdellah AH, Al-Amir Bassiony M. Cognitive profile in patients with bronchial asthma and chronic obstructive pulmonary disease (COPD). Egypt Ear Nose Throat Allied Sci. 2017;18(1):61-65

21. Al-Tahan AM, Hussain AH, Kabiraj MM, et al. Evoked and event related potentials in chronic respiratory failure. Neurosciences. 2002 7(3):179-183.

22. Barnes PJ. The cytokine network in COPD. Am J Respir Cell Mol Biol. 2009;41:631-638

23. Austin V, Crack PJ, Bozinovski S, Miller AA, Vlahos R. COPD and stroke: are systemic inflammation and oxidative stress the missing links? Clin Sci. 2016;130(13):1039-1050.

24. Barnes PJ, Celli BR. Systemic manifestations and comorbidities of COPD. Eur Respir J. 2009;33(5):1165-1185.

25. Johnstone BM, Sellick PM. The peripheral auditory apparatus. $Q R e v$ Biophys. 1972;5(1):1-57.

26. Nakano S, Imamura S, Tokunaga K, Tsuji S, Hashimoto I. Evoked potentials in patients with chronic respiratory insufficiency. Intern Med. 1997;36(4):270-275.

27. Barbieri S, Fayoumi Z, Berardinelli P, et al. Evidence for a subclinical involvement of the central nervous system in mild or moderate chronic respiratory insufficiency. Electromyogr Clin Neurophysiol. 1996;36(2):67-72.
28. Andreou G, Vlachos F, Makanikas K. Effects of chronic obstructive pulmonary disease and obstructive sleep apnea on cognitive functions: evidence for a common nature. Sleep Disord. 2014;2014:1-18.

29. Karamanli H, Ilik F, Kayhan F, Pazarli AC. Assessment of cognitive impairment in long-term oxygen therapy-dependent COPD patients. Int J Chron Obstruct Pulmon Dis. 2015;10:2087-2094.

30. Li J, Huang Y, Fei GH. The evaluation of cognitive impairment and relevant factors in patients with chronic obstructive pulmonary disease. Respiration. 2013;85(2):98-105.

31. Zhou G, Liu J, Sun F, et al. Association of chronic obstructive pulmonary disease with cognitive decline in very elderly men. Dement Geriatr Cogn Dis Extra. 2012;2:219-228.

32. Cavinato M, Rigon J, Volpato C, Semenza C, Piccione F. Preservation of auditory P300-like potentials in cortical deafness. PLoS One. 2012;7(1):e29909.

33. Howe AS, Bani-Fatemi A, de Luca V, Luca DV. The clinical utility of the auditory P300 latency subcomponent event-related potential in preclinical diagnosis of patients with mild cognitive impairment and Alzheimer's disease. Brain Cogn. 2014;86:64-74.

34. Kamel TB, Abd Elmonaem MT, Khalil LH, Goda MH, Sanyelbhaa H, Ramzy MA. Children with chronic lung diseases have cognitive dysfunction as assessed by event-related potential (auditory P300) and Stanford-Binet IQ (SB-IV) test. Eur Arch Otorhinolaryngol. 2016;273(10):3413-3420.

35. Hung WW, Wisnivesky JP, Siu AL, Ross JS. Cognitive decline among patients with chronic obstructive pulmonary disease. Am J Respir Crit Care Med. 2009;180(2):134-137.

36. Guo RB, Sun PL, Zhao AP, et al. Chronic asthma results in cognitive dysfunction in immature mice. Exp Neurol. 2013;247:209-217. 


\section{Supplementary material}

A

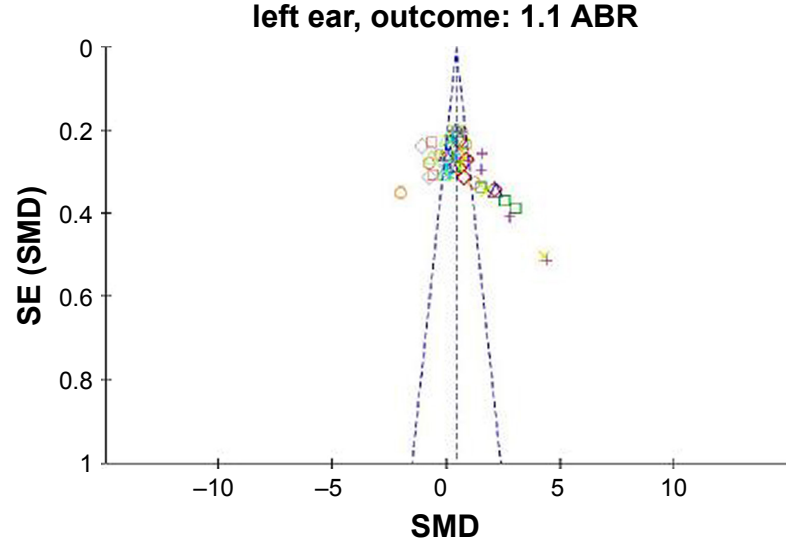

\begin{tabular}{|ccccc|}
\hline$\diamond$ Wave I & $\triangle$ Wave III & + Wave V & IPL I-V & $\square$ Amplitude Va \\
$\square$ Wave II & Wave IV & * IPL I-III & IPL III-V & $\triangle$ Amplitude V/Va \\
\hline
\end{tabular}

C

(1)

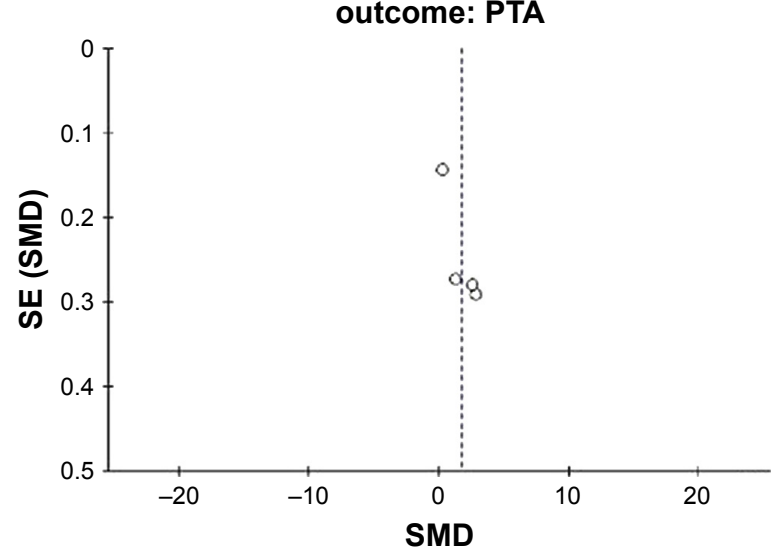

B

Funnel plot of comparison:

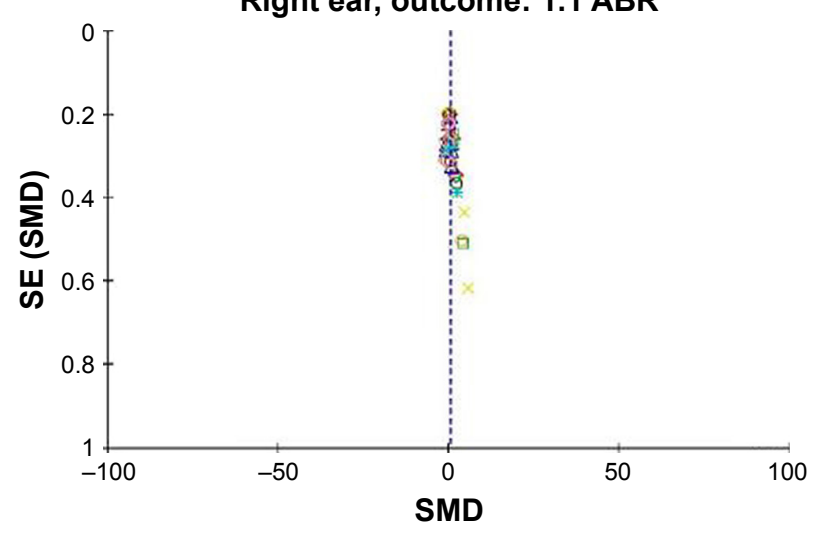

\begin{tabular}{|llcll|}
\hline OWave I & $\square$ Wave III & Wave V & * IPL I-V & Amplitude Va \\
$\diamond$ Wave II & $\triangle$ Wave IV & + IPL I-III & IPL III-V & $\square$ Amplitude V/Va \\
\hline
\end{tabular}

D

Funnel plot of comparison:

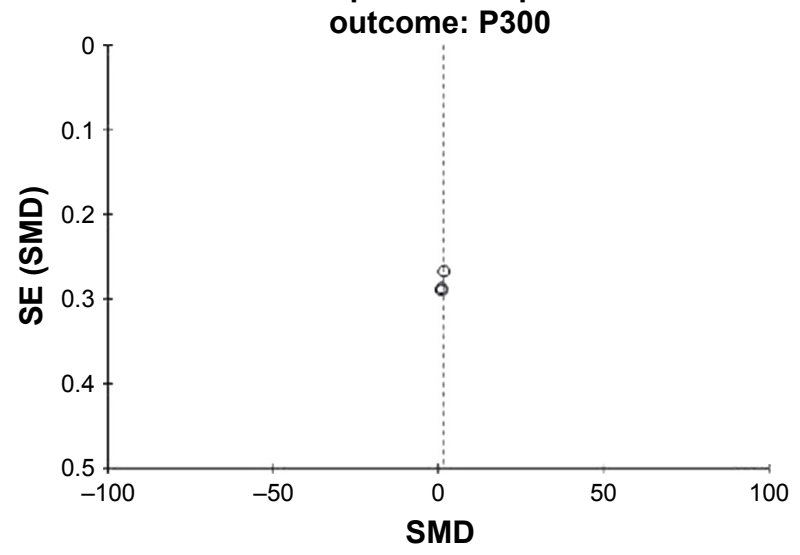

Figure SI Potential sources of bias in this meta-analysis, funnel plots of comparison in both group and sub-group analysis (A-D).

Abbreviations: ABR, auditory brainstem response; PTA, pure tone audiometry; SE, standard error; SMD, standardized mean difference.

\section{Publish your work in this journal}

The International Journal of COPD is an international, peer-reviewed journal of therapeutics and pharmacology focusing on concise rapid reporting of clinical studies and reviews in COPD. Special focus is given to the pathophysiological processes underlying the disease, intervention programs, patient focused education, and self management protocols.

\section{Dovepress}

This journal is indexed on PubMed Central, MedLine and CAS. The manuscript management system is completely online and includes a very quick and fair peer-review system, which is all easy to use. Visit http://www.dovepress.com/testimonials.php to read real quotes from published authors. 